\title{
KAJIAN FAKTOR-FAKTOR PENYEBAB KEMATIAN BAYI DI KOTA PADANG
}

\author{
Shantrya Dhelly Susanty ${ }^{1}$, Salmiah Agus ${ }^{2}$, \\ ${ }^{1}$ Program Studi Magister Ilmu Kesehatan Masyarakat, STIKes Fort De Kock, Bukittinggi, \\ Sumatera \\ Barat,Jl.Balai Bahar Kamil Bukittinggi \\ shantryadhelly@gmail.com
}

Submitted: 26-07-2017, Reviewer: 23-08-2017, Accepted: 31-03-2018

\begin{abstract}
ABSTRAK
Kematian bayi adalah kelmatian yang terjadi antara saat setelah bayi lahir sampai bayi belum berusia tepat satu tahun(0-12 buan). Jumlah kematian bayi tahun 2014 di Kota Padang adalah 108 bayi, tahun 2015 kematian bayi sebanyak 96 bayi. Penelitian ini dengan metode mixed methods, dengan sequential explanatory design. Tujuan untuk mengetahui faktor-faktor penyebab kematian bayi(0-12 Bulan) di Kota Padang bulan Januari -Agustus tahun 2016. Sampel penelitian secara total populasi. Informan ibu yang mengalami kematian bayi dan kepala bidang KIA di Puskesmas. Analisis data digunakan analisis univariat, bivariat, multivariat dan analisis kualitatif Hasil penelitian ini terdapat hubungan status gizi ibu, usia kehamilan < 37 minggu, dan BBLR dengan penyebab kematian bayi. Sedangkan kualitas ANC tidak ada hubungan. Variabel paling berpengaruh BBLR. Hasil wawancara fasilitas kesehatan sudah lengkap, kegiatan dan program yang dilakukan belum optimal. Suami dan keluarga memberikan dukungan kehamilan dan persalinan.Kesimpulan terdapat hubungan status gizi, usia kehamilan $<37$ minggu, dan BBLR dengan penyebab kematian bayi. Variabel berpengaruh adalah BBLR. Hasil wawancara fasilitas kesehatan sudah lengkap, kegiatan dan program yang dilakukan belum optimal.Diharapkan kepada Puskesmas lebih menjalankan promosi kesehatan, meningkatkan pelayanan, dan kegiatan untuk menurunkan kematian bayi.

Kata kunci : bayi , Kematian
\end{abstract}

\begin{abstract}
ABSTRACK
Infant mortality is death what happened between when after the baby birth to baby have not aged exactly one year ( 0-12 months). The number of deaths babies in 2014 in the city the is 108 baby, while in 2015 the number of deaths baby 96 baby. The research by a method of mixed methods, with the design sequential explanatory design. The purpose of know the factor-factor cause of death baby in the Padang city of the january - august 2016. The study sample in total population. Informants was the mother that experienced the death of infants and head of the KIA puskesmas. An analysis of the data used was an analysis univariat, bivariat, multivariate and analysis of qualitative.Result of this research there is the relationship between nutritional status of mothers, the gestational age \& it; 37 weeks of gestation, and bblr to the cause the death of an infant. While the quality of the ANC there was no connection. Variable has the most influence is BBLR. The results of in-depth interviews health facilities has been fully and midwives provide this service in accordance standard, but activities and program is not yet optimal. Husband and family in support of the pregnancy and childbirth. Conclusion there are the nutritional status of relations, the gestational age it; 37 weeks of gestation, and bblr to the cause the death of an infant.Variable most influential is bblr. The results of interviews health facilities are complete, but activities and program executed optimalv not yet. Expected to the public health center is run promotion of health, improve the service, and activities to lower infant mortality. For health department in order to monitoring and supervision to lower infant mortality Keywords : Infant, Mortality
\end{abstract}




\section{PENDAHULUAN}

Pembangunan kesehatan pada hakekatnya adalah upaya yang dilakukan oleh semua komponen bangsa Indonesia yang bertujuan untuk meningkatkan kesadaran, kemauan dan kemampuan hidup sehat bagi setiap orang agar terwujud derajat kesehatan masyarakat yang setinggi-tingginya, sebagai investasi bagi pembangunan sumber daya manusia yang produktif bagi sosial dan ekonomis. Keberhasilan kesehatan sangat ditentukan oleh kesinambungan antar berbagai pihak yang telah dilaksanakan periode sebelumnya (Kemenkes.2015).

Salah satu tujuan Millenium Develop-ment Goals (MDGs) adalah mengurangi kematian anak sebesar dua per tiga jumlahnya selama periode tahun 1990 sampai dengan tahun 2015.Target SDGs pada goals ketiga tahun 2030 adalah mengakhiri kematian bayi 12 per 1000 Kelahiran hidup. (Dirjen Bina Gizi.2015).

Tahun 2012 AKB di Indonesia adalah 32/1000 kelahiran hidup,5 (Handayani.2013, Kemenkes.2015). . Pada tahun 2014 data kematian bayi di Sumatera Barat adalah 681 orang. ( Dinas Kesehatan Sumatera Barat.2013).

Menurut Dinas Kesehatan Kota Padang pada tahun 2016 jumlah kelahiran bayi dari bulan Januari - Agustus 2016 adalah 11179 , dan jumlah kematian bayi dari Januari -Agustus 2016 adalah 65 bayi ( Dinas Kesehatan Kota Padang.2015)

Penyebab kematian bayi ada 2 yaitu langsung (endogen) dan tidak langsung (eksogen). Kematian bayi endogen atau kematian neonatal disebabkan oleh faktorfaktor yang dibawa anak sejak lahir, yang diperoleh dari orang tuanya pada saat konsepsi . Kematian bayi yang berasal dari kondisi bayinya sendiri yaitu BBLR, bayi prematur, dan kelainan koagenital. Kematian bayi yang dibawa sejak lahir adalah asfiksia. Kematian bayi eksogen atau kematian post-neonatal disebabkan oleh faktor-faktor yang berkaitan dengan pengaruh lingkungan luar ( Manuaba.2007).

Hasil penelitian Gholam R,S tahun

2008 bahwa penyebab kematian bayi di Birjand ada hubungan dengan orang tua yaitu tingkat pendidikan, ibu kecanduan, usia ibu pada kehamilan, prematur, BBLR, jenis melahirkan dan menyusui secara ekklusif. Menurut Washington State Department of Health tahun 2013 penyebab kematian bayi di Negara Whasington adalah kualitas antenatal care (ANC) yang rendah, pelayanan preventif, dan sosial ekonomi yang rendah. Hasil penelitian Ferial.W.Eddyman tahun 2011 hasil pengujian statistik hubungan antara status gizi ibu berdasarkan ukuran Lingkar Lengan Atas (LILA) dengan berat badan lahir bayi diperoleh bahwa terdapat hubungan yang bermakna antara status gizi ibu berdasarkan ukuran Lingkar Lengan Atas (LILA) dengan berat badan lahir bayi. Menurut penelitian Kiplogat M.K. tahun 2009 di Kenya bahwa yang mempengaruhi kualitas ANC adalah frekuensi kunjungan, waktu tunggu, beban pasien, kepatuhan standar penyediaan layanan dan jumlah pelatihan.

Hasil penelitian Zubaidah (2005) yang menunjukkan bahwa terdapat hubungan yang signifikan antara berat bayi lahir rendah dengan kematian neonatal dini dengan $\mathrm{OR}=1,32$, yang artinya bayi berat lahir rendah mempunyai risiko 1,32 kali mengalami kematian neonatal dibandingkan tidak BBLR. Hasil penelitian di atas sejalan juga dengan yang dikatakan oleh More tahun 2011, tentang pemanfaatan pelayanan kesehatan oleh ibu hamil saat melahirkan di Nigeria, bahwa dari faktor jarak rumah ke Puskesmas, sarana transportasi, biaya transportasi, pelayanan di fasilitas kesehatan, sikap petugas dan ketersediaan tenaga yang memberi pelayanan, faktor yang sangat berpengaruh adalah faktor jarak dan biaya (ekonomi). penelitian dari Burhaeny tahun

2013, didapatkan dari 48 responden yang memanfaatkan pelayanan antenatal 
terdapat $67,4 \%$ responden yang mendapat dukungan dari keluarga, sedangkan dari 39 responden yang kurang memanfaatkan pelayanan antenatal terdapat 56,8 \% yang tidak mendapat dukungan dari keluarga.Berdasarkan latar belakang diatas, maka peneliti tertarik untuk melakukan penelitian tentang "Kajian Faktor-faktor penyebab kematian bayi di Kota Padang Bulan Januari- Agustus Tahun 2016.

\section{METODE PENELITIAN}

Metode penelitian dengan metode penelitian kombinasi, dengan desain sequential explanatory design (urutan pembuktian) Tempat penelitian dilakukan di Kota Padang. Penelitian dilakukan mulai bulan Maret tahun 2016 sampai februari tahun 2017. Pengumpulan data dari bulan November-Desember 2016. Sampel penelitian adalah total populasi dari semua Ibu yang mengalami kematian bayi di Kota Padang bulan Januari- Agustus 2016 yang berjumlah 65 responden. Informan dalam penelitian adalah ibu yang mengalami kematian bayi dan kepala bidang KIA di Puskesmas, dengan teknik purposive sampling. Analisis data yang digunakan adalah analisis data kuantitatif ( univariat, bivariat, multivariat) dan analisis data kualitatif.

\section{HASIL DAN PEMBAHASAN}

Hasil penelitian pada 65 Ibu yang mengalami kematian bayi di wilayah kerja dinas kesehatan Kota Padang berdasarkan kejadian kematian bayi ditemukan 58 (89,2\%) bayi yang meninggal usia $0-12$ bulan. Menurut data di Tennesse tahun 2012, terdapat $60 \%$ kematian terjadi pada bayi.

Serupa dengan penelitian Tumondo mercy dkk tahun 2011 jumlah kematian bayi di RSUP Prof.R.D.Kandau Manado adalah 164 kasus. Sedangkan hasil penelitian Djaja Sarimawar tahun 2001 dari hasil survey kesehatan tahun 2001 didapatkan bahwa jumlah kematian bayi yaitu 466 kasus. Menurut hasil penelitian Scharlotte dkk di Afrika terdapat 1,16 juta bayi di Afrika yang meninggal pertama kehidupan. 
Tabel 1.

Distribusi Frekuensi Kematian Bayi, Status gizi ibu, Usia Kehamilan ibu, Kualitas ANC ibu dan bayi dengan BBLR di Kota Padang Bulan Januari - Agustus Tahun 2016

\begin{tabular}{|c|c|c|c|}
\hline No & Variabel & $\mathbf{F}$ & $\%$ \\
\hline \multirow[t]{3}{*}{1} & Kematian Bayi & & \\
\hline & Bayi meninggal umur $0-12$ bulan & 58 & 89,2 \\
\hline & Bayi meninggal IUFD & 7 & 10,8 \\
\hline \multirow[t]{3}{*}{2} & Status Gizi Ibu & & \\
\hline & Gizi tidak baik & 42 & 64,6 \\
\hline & Gizi baik & 23 & 35,4 \\
\hline \multirow[t]{3}{*}{3} & Usia Kehamilan & & \\
\hline & Berisiko & 45 & 69,2 \\
\hline & Tidak Berisiko & 20 & 30,8 \\
\hline \multirow[t]{3}{*}{4} & Kualitas ANC & & \\
\hline & Tidak Baik & 36 & 55,4 \\
\hline & Baik & 29 & 44,6 \\
\hline \multirow[t]{3}{*}{5} & Bayi dengan BBLR & & \\
\hline & BBLR & 44 & 67,7 \\
\hline & Tidak BBLR & 21 & 32,3 \\
\hline
\end{tabular}


Sedangkan menurut penelitian Marian F dkk tahun 2010 bahwa kematian bayi di Amerika 38\% lebih tinggi dari pada di Swedia karena angka kelahiran anak yang masih tinggi. Menurut Unicef tahun 2009 bahwa sebanyak 86\% kematian bayi yang terjadi di Ibukota Newborn. Menurut peneliti kematian bayi di Kota Padang masih tinggi, walaupun belum sampai 1 tahun. Dari hasil penelitian faktor penyebab kematian bayi di Kota Padang yaitu faktor endogen yang terdiri dari BBLR, usia kehamilan $<37$ minggu dan status gizi Ibu. Menurut hasil wawancara penyebab kematian bayi di Kota Padang adalah BBLR, ibu yang jarang mengikuti posyandu, status gizi ibu, faktor persalinan dengan letak sungsang dan ibu yang tidak mau dirujuk ke rumah sakit. Agar target SDGs tercapai maka kita harus tahu apa penyebab dan cara mengatasinya. Tindakan yang dilakukan adalah melakukan Continuum of care dengan melakukan kegiatan berkelanjutan yang dimulai dari sebelum masa hamil, masa kehamilan, persalinan dan nifas.

$\begin{array}{lrr}\text { Komponen } & \text { model persalinan } \\ \text { berkelanjutan dapat } & \text { dilakukan } & \text { dengan } \\ \text { persalinan di fasilitas } & \text { kesehatan yang }\end{array}$ memenuhi standar, menjamin penduduk miskin untuk bersalin di fasilitas kesehatan, membangun jaringan rujukan antara fasilitas kesehatan ( BPS dan Puskesmas) dengan Rumah Sakit pemerintah ataupun swasta, menerapkan penjaminan kualitas pelayanan di Puskesmas, menjalankan strategi promosi, menjalankan system surveilens kematian neonatal, dan membangun system akreditasi untuk standar pelayanan persalinan dan rujukan di fasilitas kesehatan.

Hasil penelitian didapatkan pada 65 Ibu yang mengalami kematian bayi di wilayah kerja dinas kesehatan Kota Padang berdasarkan status gizi ibu dari 65 responden terdapat $42(64,6 \%)$ responden dengan gizi tidak baik yang dilihat dari LILA ibu. Serupa dengan penelitian Ferial di Makassar tahun 2011 menunjukkan bahwa dari $192 \mathrm{ibu}$ terdapat $148 \mathrm{ibu}(77,1 \%)$ non kek (lila $\geq 23,5 \mathrm{~cm})$, dan $44 \mathrm{ibu}(22,9 \%)$ kekurangan energi kronik (lila $<23,5$ ). Hasil penelitian Mariyatul dkk tahun 2012 menjelaskan bahwa sebanyak $50 \%$ Ibu hamil yang mengalami kejadian lahir mati memiliki LILA berisiko.

Menurut peneliti tidak baiknya status gizi Ibu yang dilihat dengan LILA dikarenakan oleh Ibu yang tidak menjaga asupan makanan saat hamil. Ini terbukti dari wawancara mendalam yang dilakukan bahwa informan menjawab selama hamil nafsu makannya berkurang. Padahal status gizi ibu hamil adalah makanan atau zat-zat gizi yang di butuhkan oleh seorang ibu yang sedang hamil baik pada trimester I, trimester II, dan trimester III dan harus cukup jumlah dan mutunya dan harus di penuhi dari kebutuhan makan sehari-hari sehingga janin yang dikandungnya dapat tumbuh dengan baik serta tidak mengalami gangguan dan masalah.

Oleh karena itu untuk mengurangi status gizi tidak baik ibu hamil harus menjaga nutrisi selama kehamilan dengan makan makanan yang bergizi dan bagi tenaga kesehatan memberikan penyuluhan yang dilakukan sejak awal pemeriksaan kehamilan dan setiap kali periksa kehamilan, menganjurkan Ibu rutin melakukan pemeriksaan kehamilan, menganjurkan Ibu istirahat cukup dan pemberian leaflet tentang gizi seimbang bagi Ibu hamil.

Berdasarkan Hasil penelitian pada 65 Ibu yang mengalami kematian bayi di wilayah kerja dinas kesehatan Kota Padang berdasarkan usia kehamilan $<37$ minggu terdapat $45(69,2 \%)$ responden dengan berisiko. Hasil penelitian Frilasari dkk tahun 2016 menunjukkan bahwa sebagian besar usia kehamilan kurang bulan yaitu sebanyak 13 orang $(59,1 \%)$. menurut Unicef tahun 2009 bahwa $27 \%$ bayi yang meninggal di Newborn penyebabnya adalah usia kehamilan $<37$ minggu.

Menurut peneliti Usia kehamilan yang 
mengalami kejadian kematian bayi terbanyak yaitu pada $<37$ minggu. Bayi lahir kurang bulan mempunyai organ dan alat-alat tubuh yang belum berfungsi normal untuk bertahan hidup diluar rahim. Makin muda umur kehamilan, fungsi organ tubuh bayi makin kurang sempurna, prognosis juga semakin buruk.

Untuk mengurangi kematian bayi dengan usia kehamilan $<37$ minggu maka kita anjurkan ibu hamil untuk menjaga nutrisi selama kehamilan. Apabila nutrisi ibu baik maka perkembangan janin juga baik dan akan terhindar dari berat badan bayi kurang dan tidak mengalami kematian bayi.

Berdasarkan Hasil penelitian pada 65 Ibu yang mengalami kematian bayi di wilayah kerja dinas kesehatan Kota Padang, dari 65 responden terdapat 36 (55.4\%) responden dengan kualitas ANC tidak baik.

Serupa dengan penelitian Anwar M.C tahun 2005 bahwa proporsi responden yang mendapatkan kualitas ANC baik pada kelompok kasus 52,6\% lebih kecil dibandingkan kelompok control 86,3\%. adanya kualitas ANC yang tidak baik dikarenakan kualitas pelayanan kesehatan disamping dapat dilihat dari sudut pemanfaatan jasa pelayanan, juga dapat diukur dari kualitas pemberi pelayanan. Kesehatan pelayanan antenatal yang diberikan oleh petugas yang dijabarkan dalam jenis-jenis pemeriksaan atau pelayanan yang diperoleh ibu hamil selama memanfaatkan pelayanan antenatal, Untuk mengurangi kualitas ANC yang tidak baik maka sebagai tenaga kesehatan kita harus lebih meningkatkan persalinan difasilitas kesehatan yang memenuhi standar, menjalankan strategi promosi kesehatan, dan melakukan kunjungan rumah bagi Ibu- Ibu yang tidak datang ke posyandu.

Berdasarkan Hasil penelitian pada 65 Ibu yang mengalami kematian bayi di wilayah kerja dinas kesehatan Kota Padang, terdapat dari 65 responden terdapat 44 bayi ( $67,7 \%$ ) bayi dengan BBLR.

Hasil penelitian ini juga sebanding dengan penelitian di Afrika dengan prevelensi BBLR sebesar 8\% tahun 2000 .

Tabel 2.

Hubungan status Gizi Ibu, usia kehamilan baxi <37 minggu, kualitas ANC, BBLR dengan kematian bayi (0-12 Bulan) Di Kota Padang Bulan Januari -Agustus 2016

\begin{tabular}{|c|c|c|c|c|c|c|c|c|}
\hline & \multicolumn{4}{|c|}{ Kematian Bayi } & \multirow{3}{*}{$\mathrm{F}$} & \multirow{3}{*}{$\%$} & \multirow{3}{*}{ P-value } & \multirow{3}{*}{ OR $95 \% \mathrm{Cl}$} \\
\hline & \multicolumn{2}{|c|}{$\begin{array}{c}\text { Bayi meninggal } \\
0-12 \text { bulan }\end{array}$} & \multicolumn{2}{|c|}{$\begin{array}{c}\text { Bayi meninggal } \\
\text { IUFD }\end{array}$} & & & & \\
\hline & $n$ & $\%$ & $n$ & $\%$ & & & & \\
\hline \multicolumn{9}{|l|}{ Status Ibu } \\
\hline Gizi buruk & 41 & 37,5 & 1 & 4,5 & 42 & 100 & \multirow{2}{*}{0,006} & 14,471 \\
\hline Gizi baik & 17 & 20,5 & 6 & 2,5 & 23 & 100 & & $(1-129.453)$ \\
\hline \multicolumn{9}{|l|}{ Usia } \\
\hline \multicolumn{9}{|l|}{$\begin{array}{l}\text { Kehamilan< } \\
37 \text { minggu }\end{array}$} \\
\hline Berisiko & 43 & 40,2 & 2 & 4,8 & 45 & 100 & \multirow{2}{*}{0,025} & 7,167 \\
\hline Tidak Berisiko & 15 & 17,8 & 5 & 2,2 & 20 & 100 & & $(1-40,911)$ \\
\hline \multicolumn{9}{|l|}{ Kualitas ANC } \\
\hline Tidak Baik & 32 & 32,1 & 4 & 3,9 & 36 & 100 & \multirow{2}{*}{1,000} & 0,923 \\
\hline Baik & 26 & 25,9 & 3 & 3,1 & 29 & 100 & & $(0-4,499)$ \\
\hline \multicolumn{9}{|l|}{ Berat Bayi } \\
\hline BBLR & 43 & 39,3 & 1 & 4,7 & 44 & 100 & 0,004 & 17,200 \\
\hline Tidak BBLR & 15 & 18,7 & 6 & 2,3 & 21 & 100 & & $(1-154,777)$ \\
\hline
\end{tabular}

Menurut asumsi peneliti masih Sedangkan menurut UNICEF dan 
WHO 2009 hasil penelitian di Johanburg, Afrika selatan prevelensi BBLR sebesar $15 \%$ yang artinya mempunyai angka kematian bayi yang masih tinggi. Menurut penelitian Sonia L.dkk tahun 2014 di Brazil terdapat 8,2 \% bayi yang lahir dengan premature dan BBLR. Serupa dengan penelitian di Negara Nepal dengan studi retrospektif pada 816 persalinan bulan April -Maret 2008 terdapat 76,5\% kematian perinatal dini pada bayi dengan BBLR.

Menurut asumsi peneliti untuk mengurangi bayi yang lahir dengan BBLR tenaga kesehatan harus lebih memberikan promosi kesehatan tentang gizi yang baik bagi Ibu hamil, risiko kehamilan kecil 37 minggu. Untuk ibu hamil agar selalu menjaga asupan makanan selama kehamilan dan menjaga kehamilan agar tidak melahirkan berisiko.

\section{Hubungan status gizi Ibu dengan kematian bayi di Kota Padang bulan Januari-Agustus 2016}

Hasil analisis hubungan status gizi Ibu dengan kematian bayi diperoleh diperoleh $\mathrm{p}=0,006$ maka dapat disimpulkan ada hubungan yang signifikan antara status gizi Ibu dengan penyebab kematian bayi 0-12 bulan. Dari

hasil $\mathrm{OR}=14,471$ yang artinya $\mathrm{Ibu}$ yang mempunyai status gizi tidak baik mempunyai peluang 14 kali untuk mengalami kematian bayi (0-12 bulan), dibandingkan dengan Ibu yang memiliki status gizi baik.

Penelitian ini sejalan dengan hasil penelitian Ferial.W.Eddyman tahun 2011 hasil pengujian statistik hubungan antara status gizi ibu berdasarkan ukuran Lingkar Lengan Atas (LILA) dengan berat badan lahir bayi diperoleh hasil uji korelasi koefisien dengan tingkat signifikansi $\mathrm{p}=0,0005(\mathrm{p}<0,05)$.

Bertolak belakang dengan penelitian Erna Kusrini tahun 2012 hasil uji Chi Square dengan Confidence Interval 95\% $(0,222-2,257)$ menunjukkan nilai $p$ sebesar 0,557 ( $\mathrm{p}>\alpha 0,05)$, maka Ha ditolak. Dapat disimpulkan bahwa tidak ada hubungan antara Lingkar Lengan Atas (LILA) pada ibu hamil dengan kejadian kematian bayi di Kabupaten Sukoharjo. hasil wawancara yang dilakukan informan menjelaskan nafsu makan maka LILA ibu tidak bertambah dan asupan untuk janin akan berkurang.

2. Hubungan usia kehamilan penyebab kematian bayi $<37$ minggu di Kota Padang bulan Januari -Agustus 2016.

Hasil uji analisis hubungan usia kehamilan ibu $<37$ minggu dengan penyebab kematian bayi diperoleh $\mathrm{p}=0,025$ maka dapat disimpulkan ada hubungan yang signifikan usia kehamilan dengan penyebab kematian bayi 0-2 bulan. Dari hasil $\mathrm{OR}=7,167$ yang artinya $\mathrm{Ibu}$ yang usia kehamilan berisiko mempunyai 7 kali mengalami kematian bayi 0-12 bulan dibandingkan dengan Ibu yang memiliki usia kehamilan tidak berisiko..

Serupa dengan penelitian Juliana dkk tahun 2009 berdasarkan hasil perhitungan Odds Ratio diperoleh $\mathrm{OR}=6,750$ tingkat kepercayaan $95 \%$ dengan interval 2,06522,060 yang berarti bayi dengan usia kehamilan $<37$ minggu memiliki risiko 6,750 kali mengalami kematian neonatal dibandingkan bayi dengan usia kehamilan 37-41 minggu. Menurut hasil penelitian Haksari,E.L dan Sarjono,A tahun 2001 bahwa persalinan kurang bulan mempunyai kontribusi kematian neonatal dini yang sangat penting. Penelitian menunjukkan adanya hubungan yang kuat antara usia kehamilan dan kematian neonatal.

Usia kehamilan berhubungan dengan nutrisi ibu saat hamil. Apabia ibu menjaga nutrisi saat hamil maka tidak berisiko melahirkan kecil 37 minggu. Masalah kesehatan seorang ibu berpengaruh dengan kualitas anak yang di kandungnya. Anak yang dilahirkan dari rahim ibunya yang sehat mempunyai pertumbuhan dan perkembangan yang sehat, sebaliknya jika 
kesehatan ibu memiliki gangguan maka anak akan mengalami petumbuhan dan perkembangan

\section{Hubungan kualitas ANC dengan penyebab kematian bayi di Kota Padang bulan Januari-Agustus 2016}

Hasil uji analisis hubungan kualitas ANC dengan kematian bayi 0-12 bulan didapatkan $p=1,000$. Maka dapat disimpulkan tidak ada hubungan yang signifikan antara kualitas ANC dengan kematian bayi $0-12$ bulan. Dari hasil $\mathrm{OR}=$ 0,923 , yang artinya Ibu yang kualitas ANC tidak baik berpeluang 0 kali untuk mengalami kematian bayi $0-12$ bulan dibandingkan ibu dengan kualitas ANC baik.

Penelitian ini bertolak belakang dengan penelitian yang dilakukan oleh Kiplogat M.K. tahun 2009 di Kenya bahwa yang mempengaruhi kualitas ANC adalah frekuensi kunjungan, waktu tunggu, beban pasien, kepatuhan standar, penyediaan layanan dan jumlah pelatihan. Penelitian Wulansari dan Sulistiowati tahun 2012 bahwa adanya hubungan antara kualitas ANC dengan kepuasan pasien, dimana pelayanan ANC baik 27 orang $(55 \%)$, tingkat kepuasan pasien adalah $55 \%$.

Menurut peneliti tidak ada hubungan antara kualitas ANC dengan penyebab kematian bayi di Kota Padang karena dari hasil wawancara mendalam dengan informan pemegang program KIA menjelaskan bahwa standar pelayanan antenatal di Kota Padang menggunakan standar 10T yang mana sudah berlaku pada semua Puskesmas, Puskesri dan BPS. Ada salah satu Puskesmas yang telah menerapkan standar pelayanan pemeriksaan HIV/AIDS. Untuk pemeriksaan ANC yang dilakukan oleh Ibu hamil pun mereka tidak hanya melakukan pemeriksaan di Puskesmas atau BPS tetapi ke Dokter spesialis.

\section{Hubungan BBLR kematian bayi di Kota Padang bulan Januari -}

\section{Agustus 2016.}

Berdasarkan analisis diperoleh hasil dari 44 responden yang BBLR terdapat 43 $(39,3 \%)$ yang mengalami kematian bayi 0 12 bulan. Sedangkan dari 21 responden yang tidak BBLR terdapat $15(18,7 \%)$ responden yang mengalami kematian bayi 0-12 bulan. Dari hasil uji statistik diperoleh $\mathrm{p}=0,004$. Maka ada hubungan yang signifikan antara bayi BBLR dengan penyebab kematian bayi 0-12 bulan, dimana $p=0,004<0,05$. Dari hasil OR = 17,200 yang artinya Ibu yang bayi dengan BBLR mempunyai peluang 17 kali untuk mengalami kematian bayi 0-12 bulan dibandingkan dengan ibu yang tidak BBLR.

Serupa dengan penelitian Chowdhury et.all tahun 2005, bahwa BBLR merupakan penyebab utama yang membeikan kontribusi sekitar sepertiga dari semua kematian bayi dini pada daerah pedesaan di Bangladesh. Selain itu suatu penelitian Lancet tahun 2010 di India yang menghasilkan bahwa $78 \%$ kematian bayi di India disebabkan oleh BBLR, prematuritas, inspeksi neonatal dan asfiksia.

Menurut peneliti BBLR berhubungan dengan penyebab kematian bayi karena bayi dengan BBLR merupakan keadaan yang sangat rentan dan memiliki potensi yang sangat besar untuk mudah mengalami gangguan, seperti gangguan mental dan fisik sehingga mengganggu tumbuh kembang. Jika tidak ditangani dengan benar maka akan terjadi kematian Berdasarkan tabel 5.6, maka dapat disimpulkan bahwa variabel -variabel yang masuk ke tahap selanjutnya adalah status gizi Ibu, usia kehamilan, dan BBLR dikarenakan mempunyai p-value $<0,25$. Dan setelah dilakukan analisis multivariat didapatkan variabel yang paling berpegaruh dengan kematian bayi di Kota 
Tabel 3.

Hasil analisa Conditional Logistic Regression Status Gizi Ibu, Usia Kehamilan Bayi < 37 minggu dan BBLR dengan Kematian Bayi (0-12 bulan) Januari - Agustus 2016

\begin{tabular}{cccccc}
\hline \multirow{2}{*}{ Kematian Bayi 0-12 bulan } & \multirow{2}{*}{ variabel } & p- & \multirow{2}{*}{ value } & OR & \multicolumn{2}{c}{$95 \% \mathrm{Cl}$ for exp (B) } \\
\cline { 6 - 6 } & & & Lower & Upper \\
\hline & Status gizi ibu & 0,003 & 13,080 & 1,140 & 150,057 \\
& Usia kehamilan & 0,014 & 5,287 & 0,620 & 45.073 \\
& BBLR & 0,001 & 21,634 & 1,844 & 253,791 \\
\hline
\end{tabular}

Padang bulan Januari-Agustus 2016 adalah BBLR dengan nilai p-value yang paling rendah yaitu 0,001 . Hasil penelitian lain yang sesuai oleh Yunus pada tahun 2009 di Konawe Selatan yang menyatakan bahwa neonatal yang dilahirkan dengan berat badan lahir kurang 2500 gram berisiko 12,732 kali lebih besar untuk mengalami kematian neonatal dibanding neonatal yang dilahirkan dengan berat badan lahir $\geq 2500$ gram (OR=12,732;CI95\%: 4,197-38,622).

Hasil penelitian lain yang mendukung yaitu penelitian yang dilakukan oleh Prabamurti di Kecamatan Losari Kabupaten Brebes (2008) menyatakan bahwa analisis dengan OR diperoleh nilai $\mathrm{OR}=6,12$ yang berarti bahwa bayi yang lahir dengan berat lahir kurang dari 2500 gram memiliki risiko kematian neonatal

6,12 kali lebih besar dibanding bayi yang lahir dengan berat lahir 2500 gram atau lebih. Serupa dengan penelitian yang dilakukan oleh Haque tahun 2008 yang meneliti Role of zink in low birth weight neonatal, berdasarkan hasil penelitian insiden BBLR merupakan penyebab utama kematian bayi dan morbilitas.

Hasil penelitian Scharlotte W et.all di Afrika bahwa penyebab banyaknya bayi yang meninggal di Afrika faktor yang paling mempengaruhi adalah BBLR. Di Negara afrika untuk menangani kematian bayi dengan BBLR ini tenaga kesehatan melakukan tindakan sepeti mengidentifikasi masalah BBLR, menilai tanda bahya untuk merujuk kasus, memberikan piala bagi yang mau menyusui, melakukan metode kangguru kepada ibu terhadap bayi yang BBLR, dan memberikan promosi kesehatan bagi ibu yang bayi tidak mau menyusui. Menurut hasil penelitian Unicef tahun 2009 bahwa $60-80 \%$ kematian bayi faktor yang paling dominan dengan kematian bayi adalah bayi dengan BBLR.

Menurut peneliti banyaknya bayi yang lahir dengan BBLR di sebabkan oleh status gizi ibu dan usia kehamilan kecil 37 minggu masih yang masih tinggi. Apabila status gizi ibu yang tidak baik dan usia kehamilan yang kecil 37 minggu maka bayi tersebut akan rentan dengan BBLR. Berdasarkan wawancara mendalam menjelaskan bahwa Ibu hamil jarang melakukan kegiatan Posyandu yang diadakan Puskesmas. Dengan kurangnya kunjungan Posyandu berarti ibu hamil kurang mendapatkan informasi dan pengetahuan tentang kehamilannya., sehingga Ibu kurang menjaga asupan makanan dan kesehatan bayinya.

Hal inilah yang menyebabkan banyaknya bayi yang lahir dengan BBLR. Kesehatan bayi yang dilahirkan oleh ibu berhubungan dengan bagaimana ibu hamil menjaga asupan makanan dan kandungannya. Cegah kelahiran bayi berat lahir rendah dengan peduli pada diri sendiri, yaitu perbaiki status gizi prahamil dan lakukan pemeriksaan antenatal (kehamilan) secara rutin. Status gizi prahamil merupakan faktor yang sangat memengaruhi kenaikan berat badan selama kehamilan. Dengan status gizi yang 
normal, ibu akan lebih mudah mencapai berat badan yang pas. Perbanyaklah konsumsi makanan yang bergizi seimbang. Penuhi asupan dari karbohidrat, protein, lemak, vitamin, dan mineral. Selain itu, cukupi kebutuhan air. Selama proses kehamilan, kebutuhan energi dan zat gizi ibu meningkat seiring bertambahnya usia kehamilan. Meskipun volume makanan rendah, kandungan zat gizi tinggi dapat menjadi salah satu solusi untuk mencukupi kebutuhan energi dan zat gizi ibu. Jika konsumsi ibu baik, potensi outcome kehamilan seperti bayi berat lahir rendah tentu berkurang .

Selain itu untuk mengurangi bayi BBLR Ada baiknya ibu untuk melakukan perencanaan keluarga, termasuk perencanaan untuk memberi jarak kelahiran pada anak. Jarak ideal adalah kurang lebih 2 tahun dari jarak kehamilan sebelumnya. Cara lainnya adalah Ada baiknya pasangan menikah menunda kehamilan jika usia istri belum genap 20 tahun. sia ibu yang terlalu muda, usia ibu di atas 40 tahun juga memiliki risiko yang sama. Hal ini karena kondisi badan serta kesehatannya sudah mulai menurun sehingga dapat memengaruhi perkembangan janin dalam rahim yang bisa mengakibatkan bayi berat lahir rendah

\section{Fasilitas kesehatan \\ Tenaga kesehatan dan kelengkapan alat}

Tenaga kesehatan adalah setiap orang yang mengabdikan diri dalam bidang kesehatan serta memiliki pengetahuan dan keterampilan melalui pendidikan di bidang kesehatan yang untuk jenis tertentu memerlukan kewenangan untuk melakukan upaya kesehatan. Fasilitas suatu alat atau sarana untuk mendukung melaksanakan tindakan atau kegiatan, pengelolaan logistik yang baik dan mudah diperoleh serta pencatatan dan pelaporan yang lengkap dan konsisten

Dari hasil penelitian diatas dapat dilihat bahwa untuk fasilitas kesehatan yang mencakup tenaga kesehatan dan kelengkapan alat yang ada di Puskesmas Kota Padang sudah berperan aktif dengan kegiatan yang diberikan tetapi belum berjalan secara optimal. Sedangkan untuk kelengkapan alat yang ada sudah sesuai dengan standar dan sudah lengkap.

Hasil penelitian sejalan dengan penelitian Ariyanti tahun 2010 dari hasil pengamatan tentang sarana dan prasarana yang ada di Puskesmas yang mendukung pelaksanaan pelayanan antenatal sudah lengkap dan pelayanan yang diberikan bidan sesuai dengan standa yang ada. Menurut penelitian Lansky Sonia dkk tahun 2014 di Brazil bahwa kematian bayi dan bayi premature di Brazil dapat dicegah dengan kualitas layanan kesehatan yang baik, perawatan selama kelahiran oleh tenaga kesehatan.

Menurut peneliti agar semua program dan kegiatan berjalan dengan lancar sebagai tenaga kesehatan kita melakukan kegiatan berkelanjutan ( continuum of care) dari sejak sebelum masa hamil, masa kehamilan, persalinan dan nifas. Kegiatan dapat berupa meningkatkan status gizi perempuan dan remaja, meningkatkan pendidikan kesehatan reproduksi remaja dimulai dari lingkup keluarga, meningkatkan konseling pra nikah untuk calon pengantin, dan meningkatkan peran aktif suami, keluarga, kader dan masyarakat dalam menjaga mutu kesehatan keluarga, sebelum dan saat hamil termasuk perencanaan persalinan dan pencegahan komplikasi (P4K) serta pemenuhan pelayanan keuarga berencana (KB).

\section{Peran petugas}

Peran bidan yang diharapkan, harus sesuai dengan kewenangan profesi bidan. Hubungan antara petugas kesehatan dengan pasien dalam hal ini masyarakat, sangat menentukan kualitas pelayanan yang diberikan oleh petugas kesehatan. Petugas kesehatan di Puskesmas harus mampu memberikan pelayanan yang optimal pada masyarakat sebagai pasien 
nya. Hasil penelitian menunjukkan bahwa peran yang diberikan oleh petugas kesehatan sudah baik.

Serupa dengan penelitian Rahayu Purwatiningsih tahun 2008 bahwa dari serangkaian data yang diperoleh di lapangan dapat menarik sebuah kesimpulan bahwa Puskesmas Jatinom telah memberikan pelayanan yang sangat baik kepada pasien, sarana dan prasarana yang ada dan diberikan sangat memuaskan, dalam proses pelayanan yang diberikan kepada pasien pun sangat ramah, bertindak cepat dan sesuai prosedur yang ada.

Menurut asumsi peneliti sebagai seorang tenaga kesehatan sangatlah penting untuk memberikan pelayanan sebelum hamil karena akan berpengaruh terhadap 1000 hari pertama kehidupan bagi anak yang dimulai sejak masa konsepsi sampai balita. Memberikan pelayanan kesehatan ibu dan anak harus menjadi kewajiban sebagai pelaksana kebidanan karena keadaan kesehatan ibu dan anak memiliki peranan yang besar sebagai indikator tingkat kesejahteraan bangsa. pelayanan kesehatan bukan hanya pengobatan secara medis saja melainkan juga berorientasi pada komunikasi karena komunikasi sangat penting dan berguna bagi pasien. Bidan harus memberikan konseling kepada Ibu hamil agar ibu hamil mengetahui apa yang dibutuhkan selama kehamilan dan mengetahui perkembangan bayi dalam kandungannya. Dengan bidan memberikan peran yang sesuai dengan tugas seorang tenaga kesehatan merupakan salah satu cara untuk menurunkan kematian bayi.

\section{Lingkungan}

Dukungan adalah suatu upaya yang diberikan kepada orang lain, baik moril maupun materil untuk memotivasi orang tersebut dalam melaksanakan kegiatan. Ibu yang mendapatkan dukungan dari suami akan lebih bersemangat dan sering memanfaatkan pelayanan antenatal. Dukungan keluarga merupakan kesediaan, kehadiran dan kepeduliaan dari keluarga untuk membantu individu merasa nyaman dan tentram dalam menjalani kehidupan sehari-harinya. Dalam upaya memanfaatkan fasilitas pelayanan kesehatan, walaupun pengetahuan dan sikap ibu baik, tetapi jika tidak ada dukungan dari keluarga maka pemanfaatan fasilitas kesehatan tidak tercapai seperti yang diharapkan. Hal ini sejalan dengan penelitian yang dilakukan oleh Nilasari tahun 2013, menyatakan bahwa terdapat hubungan antara dukungan keluarga dengan pemanfaatan pelayanan antenatal. Hal tersebut sejalan juga dengan penelitian dari Burhaeny tahun 2013 faktor determinan pemanfaatan pelayanan antenatal, didapatkan dari 48 responden yang memanfaatkan pelayanan antenatal terdapat $67,4 \%$ responden yang mendapat dukungan dari keluarga, sedangkan dari 39 responden yang kurang memanfaatkan pelayanan antenatal $56,8 \%$ yang tidak mendapat dukungan dari keluarga.

Ini berarti masih ada hubungan yang erat antara dukungan keluarga terhadap pemanfaatan pelayanan antenatal. Selain dukungan keluarga, hal yang sangat berpengaruh juga adalah dukungan dari tokoh-tokoh atau pemimpin masyarakat baik tokoh formal.

Serupa dengan penelitian Danfort et all tahun 2009 menjelaskan bahwa pentingnya peran suami dalam pengambilan keputusan terkait dengan proses persalinan dan tempat bersalin. Menurut penelitian Kim et all tahun 2010 bahwa ibu hamil yang menerima dukungan dari suami dan keluarga akan meningkatkan pelaku ibu dalam menjaga kehamilannya, sehingga ibu tidak rentan pada kehamilannya.

Penelitian Tyas tahun 2013 menunjukkan bahwa ada hubungan antara dukungan suami dan keluarga terhadap prilaku ibu hamil dalam melakukan kunjungan kehamilan. Sedangkan menurut penelitian Wahn dan Eva tahun 2008 pada komunitas wanita Swedia menyatakan bahwa wanita hamil di Swedia 
mengharapkan dukungan dari keluarga terutama dari ibu dan suami pada masa kehamilannya.

Menurut asumsi peneliti dari hasil wawancara penelitian pada informan di kota Padang terlihat bahwa dukungan yang diberikan oleh suami dan keluarga sudah baik. Dimana suami dan keluarga selalu memberikan dukungan baik selama hamil atau bersalin. Dukungan suami dan keluarga merupakan suatu keadaan yang bermanfaat bagi ibu hamil .

\section{KESIMPULAN DAN SARAN}

\section{A. Kesimpulan}

Berdasarkan hasil penelitian yang dilakukan terhadap 65 orang responden yaitu ibu yang mengalami kematian bayi di Kota Padang bulan Januari sampai Agustus tahun 2016 dan dapat ditarik kesimpulan yaitu Lebih dari separoh Ibu yang mengalami kematian bayi usia 0-12 bulan.

Lebih dari separoh Ibu yang mengalami kematian bayi mempunyai gizi tidak baik di Kota Padang bulan JanuaiAgustus 2016.

Lebih dari separoh Ibu berisiko mengalami kematian bayi usia kehamilan kecil 37 minggu. Lebih dari separoh Ibu yang mengalami kematian bayi memiliki kualitas ANC yang tidak baik.

Lebih dari separoh Ibu yang mengalami kematian bayi dengan BBLR kecil 2500 gram.

Ada hubungan yang signifikan antara status gizi ibu dengan, usia kehamilan kecil 37 minggu dan berat bayi BBLR dengan penyebab kematian bayi. Tidak ada hubungan yang signifikan antara kualitas ANC dengan penyebab kematian bayi.

Terdapat variabel yang paling berpengaruh dengan penyebab kematian bayi di kota Padang tahun 2016 yaitu bayi dengan BBLR.

Fasilitas kesehatan yang terdiri tenaga kesehatan sudah memberikan pelayanan yang sesuai dengan standar dan tanggung jawab sebagai bidan. Kegiatan dan program yang dilakukan oleh tenaga kesehatan sudah berjalan tetapi belum optimal.

\section{B. Saran}

Bagi Puskesmas di Kota Padang dapat Melakukan kegiatan UPGK ( upaya perbaikan gizi keluarga) melalui kegiatan PMT( Pemberian Makanan Tambahan) bagi Ibu hamil. Meningkatkan peran masyarakat agar program pemerintah dapat berjalan lancar dengan memberikan edukasi tentang kesehatan, khususnya tentang status gizi ibu hamil, BBLR dan kualitas ANC.

Meningkatkan edukasi antara tenaga kesehatan, pemerintah dan masyarakat agar kegiatan berjalan secara optimal dan efektif. Melakukan home care (kunjungan rumah) bagi ibu yang tidak melakukan pemeriksaan ANC, ibu yang berisiko bayi BBLR dan tidak mengikuti Posyandu.

Menganjurkan ibu hamil untuk perbaiki status gizi prahamil dan lakukan pemeriksaan antenatal (kehamilan) secara rutin agar bayi tidak BBLR. Bidan koordinator setiap Puskesmas membentuk kegiatan kelas remaja untuk mengurangi kehamilan $<37$ minggu dan status gizi yang tidak baik.

Bidan koordinator setiap Puskesmas mencatat alat-alat kesehatan yang dibutuhkan untuk melengkapi peralatan kesehatan di Puskesmas agar tidak tidak mengalami kendala saat pemeriksaan antenatal care dan persalinan Bagi dinas kesehatan agar dapat meningkatkan pelayanan secara optimal di setiap Puskesmas melalui bidan koordinator agar tercapainya target penurunan kejadian kematian bayi. Meningkatkan jenjang pendidikan bidan koordinator disetiap Puskesmas.

Dinas kesehatan lebih meningkatkan evaluasi dan monitoring terhadap semua kegiatan dan kinerja bidan disetiap Puskesmas, dan 
melakukan supervisi ke setiap Puskesmas agar semua kegiatan berjalan dengan optimal dan target penurunan kematian bayi tercapai.

\section{UCAPAN TERIMA KASIH}

Puji syukur yang tak terhingga penulis ucapkan kehadirat allah SWT yang telah melimpahkan rahmat dan hidayatnya.

Penulis mengucapkan terima kasih kepada kedua orang tua ayah dan Ibu yang telah memberikan penulis cinta dan kasih sayang yang tulus. Selain itu penulis ucapkan kepada Ibu dan Bapak pembimbing dan penguji yang telah membantu dalam menyelesaikan tesis ini. Beserta ucapan terima kasih kepada seluruh teman-teman angkatan 1 magister kesehatan yang telah memberikan semangat sehingga bisa menyelesaikan tesis ini.

\section{DAFTAR PUSTAKA}

Badan Pusat Statistik.2007. Mortalitas.

Direktorat Analisis dan

Pengembangan Statistik; (online), (http://daps.bps.go.id, diakses tanggal 11januari 2017)

Chanthanom Manithip. (2012). Quality And Util Is Ation Of Antenatal Care Services In Rural Lao Pdr. From The Department Of Women's And Children's HeaLth Division Of Obstetri Cs And Gyn A Ecolog

Care of the Newborn in Developing Countries Book 2 Chapter 2.Perinatal Mortalit.

https://www.oxfordjournals.org/our_j ournals/tropej/online/chapter2 bk2.pd f diakses tanggal 12 oktober 2016

Cut.Sri.Wahyuni.2008.hubungan faktor ibu dan pelayanan kesehatan dengan kematian perinatal di Pidie tahun

2008. Tesis: Universitas Sumatera Utara

Chowdhurry,M.S.et all. 2005. Neonatal mortality in Rural Bangladesh .jurnal an exploatorry study
Dinas kesehatan Sumbar. (2012:13-37).

Profil kesehatan provinsi

sumaterabarat Tahun 2012. Padang:

Dinas kesehatan Sumatera Barat

Dinas Kesehatan Kota Padang. ( 2013:14-

15). Profil kesehatan kota Padang:

Padang:Dinkes Kota Padang

Dirjen Bina Gizi KIA RI.( 2015).Kesehatan Dalam SDGS. Jakarta:Kemenkes

Danfort.E.J et.all.(2009: 696-703). Household decision making about delivery in health facilities: evidence from Tanzania, international centrre for diarrrrrhoel disease research Bangladesh $\mathrm{J}$ health population

Heisier, J.E. (2012:1-13). The u.s. infant mortality rate: international comparisons, underlying factors and federal program: Congressional research

Hoque A.(2009). Role of zink in low birth weight neonatal banglades medical journal.vo;.38 no 1 januari 2009. Institute of nutrrion and food science: university of Dhaka Bangladesh

Kementerian Kesehatan RI. (2015:5-9). Rencana Strategis kementrian kesehatan tahun 2015-1019. Jakarta : Kementerian Kesehatan

Kiplogat M.K.(2009).factor influencing the quality of antenatal care in public maternal and child health facilities in neorabi province Kenya. Kenya: Kunyatta university.

Kim et.all.(2010). Social support stress and practice of prenatal carre in marrid immigrant wonzen in korea: jornal of transcultural nursing

Lansky Sonia et.all (2014). Birth in Brazil survey: neonatal mortality, pregnancy and childbirth quality of care.journal

Lancet.2010.cause of neonatal and child mortalyty in India: Anationally reprresentative in belo horizonte: Brazil

Moore.2011.Unitization Of Health Care Servise By Pregnant Mothers During 
Delivery: a community based study in Negeria .east African of public health

Nila,S.( 2013). Faktor Deteminan Pemanfaatan Pelayanan Antenatal Diwilayah Kerja Puskesmas Batua Kecamatan Manggaga tesis : Makassar

Nur,I, Ansariad,dan Dwinata,I.( 2016) Kualitas Antenatal Care Pada Ibu Hamil Yang Berkunjung Kepuskesmas Togo-Togo Kabupaten Jeneponto. Tesis.Fakultas Kesmas: Universitas Indonesia

Nwaokoro, J,C.dkk. 2015. Risk Factors Associated with Infant Mortality in OwerriMetropolis, Imo State, Southeastern Nigeria. Nigeria: Science Journal of Public Health
Unicef. (2012:1-6). Ringkasan Kajian Ibu Dan Anak. united for children: Jakarta Upadyay R.D et all (2012: 291294).determinans of neonatal mortality in rrural Haryana .A retrospective population based study:indian pediactric

Wolfe, I.et all. (2014:3-25). Why children die: death in infants children and yaoung people in the UK. British association for child an adolescent

Washington State Department of Health. 2013. Infant Mortality. Health of Washington State

Wright et all.2014. ending newbron death ensurrring every baby survives, save children 1 st john"s Lane London ECIM 4AR UK+44(0)207012 